\title{
Jornalismo: uma discussão emergencial para a pesquisa acadêmica em tempos de mídia digital ${ }^{1}$
}

Nancy Nuyen Ali Ramadan (USP) ${ }^{2}$

\section{Resumo}

Este artigo é fruto de uma pesquisa pessoal em andamento e tenta compreender e analisar as recentes pesquisas acadêmicas que dão conta do jornalismo disponibilizado na Internet. A idéia é a de retomar os estudos mais aprofundados em jornalismo, tentando avançar teórica e metodologicamente na busca de um campo mais delineado e seguro para estes trabalhos na contemporaneidade. São divulgados aqui dados preliminares sobre o tema, obtidos na referida pesquisa.

Palavras-chaves : Jornalismo; jornalismo on line; teoria do jornalismo; metodologia; comunicação.

\section{Abstract}

This article is the result of an ongoing research aiming to understand and analyze recent academic production on online journalism. The main idea is to retrace the denser works on journalism, trying to go forward theoretically and methodologically in order to limit a more assured field to these studies in contemporaneity. In the present work we release some of the researches preliminary data on the subject.

Keywords: Journalism, online journalism, journalism theory, methodology; communication 
Com a chegada e o desenvolvimento da mídia digital no Brasil, o jornalismo vem sofrendo uma série de mudanças no seu fazer, em diferentes instâncias. As empresas jornalísticas são as primeiras a sofrer as conseqüências do novo cenário tecnológico, que tem como características marcantes a velocidade e a chamada interatividade. Os jornalistas começam a ocupar este novo espaço, produzindo e oferecendo publicações em pequenos sites ou como repórteres, redatores e editores trabalhando nos portais de empresas tradicionais em outras mídias que migram para a rede mundial. As transformações são radicais e velozes. É preciso dominar novas técnicas e conceber o noticiário para um novo público - o usuário da informação que navega pela Internet.

Mudam o perfil desse profissional e os critérios para a edição (aqui entendida como um processo que vai da pauta a um fechamento que, em rede, é permanente): a atualização do noticiário é imediata, sempre que se fizer necessária. Resta saber se o que temos sistematizado na academia - conceitos de jornalismo; referências para a prática, pesquisa e ensino; parâmetros éticos e estéticos - darão conta de todas essas mudanças que exigem sintonia e articulação.

Os responsáveis pela pesquisa no setor - dos quais se espera uma interpretação consistente das referidas transformações, num mundo que se pretende globalizado e interligado em rede - estariam reunindo conhecimentos teóricos e metodológicos para enfrentar esse novo desafio?

"Toda uma parte das Ciências Humanas trata com uma pretensão de rigor legítima, se não satisfeita, de fenômenos que são imprecisos, confusos e de terminologia duvidosa". (Moles, 1990: 62)

Antes mesmo da chegada da Internet, com sua capacidade de reunir informações em diversos formatos - som, imagem em movimento e texto e, para alguns, a integração desses formatos com banco de dados em um único ambiente, ou seja, a multimídia, a discussão do campo da comunicação sempre teve algum espaço no meio acadêmico e, conseqüentemente, a discussão em torno da pesquisa específica na área de jornalismo.

Fazemos ciência? A comunicação é uma ciência ou não? E o jornalismo, como habilitação da Comunicação? 
Isso significa que, ainda antes da chegada da $\mathrm{WEB}^{3}$, a pesquisa em Comunicação e, mais especificamente, em jornalismo, tanto no que diz respeito aos conceitos fundamentais quanto à metodologia utilizada, carece de maior debate.

Com o acelerado avanço tecnológico na área, parece emergencial tentarmos dimensionar com maior clareza o fazer jornalístico e seu estudo. É preciso contribuir para essa discussão que - é importante lembrar - antecede a chegada ao Brasil das novas invenções técnicas, mais particularmente de meados dos anos 80 para cá.

Uma das vertentes dessa preocupação é a de tentar compreender e analisar as recentes pesquisas que dão conta do jornalismo disponibilizado na Internet - objetivo central de trabalho de pesquisa pessoal que vem sendo realizado há aproximadamente quatro anos.

Em entrevista, às vésperas de completar 60 anos, o pesquisador Muniz Sodré falou de seu percurso acadêmico e propôs uma revisão teórica da comunicação, em face de transformações decorrentes da aceleração tecnológica, da reconfiguração das noções de tempo e espaço e dos impactos provocados pela multiplicação de "tecno-interações" nas mídias.

O propósito fundamental deste ensaio, portanto, fruto de trabalho de pesquisa pessoal em andamento, é o de tentar avançar teoricamente na busca de um campo mais delineado, conceitual e metodologicamente, para a pesquisa acadêmica, especificamente na área de jornalismo. Espera-se, ao final da pesquisa - neste ensaio vamos trabalhar com dados preliminares vislumbrar uma base mais segura para os trabalhos acadêmicos no setor.

Esta pesquisa tem como base a análise de trabalhos acadêmicos (mestrado, doutoramento e pós-doutoramento) sobre 0 jornalismo disponibilizado na Internet, realizados entre 1996 e 2003, pela comunidade científica da área de Comunicação Social, na cidade de São Paulo.

A partir deste corpus, busco detectar os aportes teóricos e metodológicos dos acadêmicos que "teorizaram" sobre o jornalismo disponibilizado em rede. Espera-se assim sistematizar - com a análise de dissertações e teses, 0 conhecimento recentemente acumulado em torno do tema; verificar os caminhos teóricos e metodológicos eleitos pelos pesquisadores; e propor referenciais teóricos e metodológicos que contemplem especialmente a 
pesquisa e o ensino de jornalismo e, em outra ponta, o fazer jornalístico neste novo espaço tecnológico e digital.

\section{Comunicação e jornalismo}

O debate em torno da pesquisa em Comunicação, mais intenso diante do avanço tecnológico observado nas últimas duas décadas, e das transformações mais recentes nos níveis econômicos, políticos e sociais da chamada "sociedade global", vem impondo uma reflexão permanente em torno do jornalismo. Porém, entendido como uma disciplina da "área" ou do "campo" da Comunicação, ele surge aparentemente frágil, tanto como prática quanto como tema de trabalhos em nível de pós-graduação. Isso porque, a Comunicação - um "guarda-chuva" que abrigaria algumas disciplinas, entre elas o jornalismo - também se mostra um espaço movediço quanto falamos em pesquisa científica. Senão, vejamos:

"Enquanto objeto de estudo, a Comunicação tem sido alvo de interesse de inúmeras disciplinas científicas, que a refletem teoricamente e analisam empiricamente, a partir dos seus respectivos paradigmas. Mas enquanto campo acadêmico, sua identidade tem se caracterizado pelo delineamento de fronteiras, estabelecidas em função dos suportes tecnológicos (mídia) que asseguram a difusão dos bens simbólicos e do universo populacional a que se destinam (comunidades/coletividades)". (Melo, 1978:. 17-18)

Um aprofundamento em torno de características e problemas relativos à constituição do campo como área de conhecimento, as tendências no meio acadêmico para o desenvolvimento da pesquisa em Comunicação e as necessidades para a produção de trabalhos de um modo geral na área, são sem dúvida, missões da Universidade, já que, comumente, o que temos de trabalhos conhecidos e encaixados na chamada Teoria da Comunicação (ou, ainda, Teorias da Comunicação), consistem em vertentes de determinadas e tradicionais linhas de pesquisas que datam do começo deste século. Da mesma maneira, o Jornalismo tem suas bases acadêmicas em estudos como 0 de Peucer e Otto Groth. Este, procurou estabelecer fundamentos para a Zeitungswissenschaft (ciência do jornalismo), também chamada de Periodika. Groth pretendeu estabelecer leis para uma ciência periodística pura e começou 
a escrever sua primeira obra, Die Zeitung, em 1910, quatro volumes publicados entre 1928 e 1930. Posteriormente, chegou até a propor os diversos ramos dessa nova ciência: técnicas de realização periodística (jornais, rádio, TV, cinema e publicidade), história do jornalismo, legislação de imprensa, estudos sobre audiência e análise de conteúdo. Antes mesmo dos estudos de Groth, temos uma tese de Tobias Peucer, também alemão, datada de 1690, na qual pondera: "(...) fica claro que os relatos jornalísticos não costumam escrever tendo em vista a posteridade senão tendo em vista a curiosidade humana. Da mesma forma, se acontece que a partir deles as coisas narradas também passam à história estritamente dita, há de se compreender que nem todos, somente uns poucos, os que foram registrados com certa acurácia e aplicação é que passam à história." (Peucer, 2004: 26)

"De Relationibus Novellis - Os Relatos Jornalísticos", tese defendida na Universidade de Leipzig em 1690, por Peucer, voltou a ser revista pelos pesquisadores. Trata-se da primeira tese sobre Jornalismo apresentada em uma universidade. Comparando Jornalismo e História, Peucer aborda temas importantes para o estudo do jornalismo, tais como noticiabilidade, credibilidade, autoria e verdade, bem como a forma dos periódicos.

Há, assim, notícias da busca de um status acadêmico para o Jornalismo. No entanto, abrigado no "campo" ou na "área" da Comunicação, ele é visto como uma disciplina. A própria Comunicação é tomada na maior parte dos estudos como uma disciplina aplicada. Vejamos o que diz Martino:

"Essa distinção entre epistemologia geral e aplicada nos permite precisar uma das grandes dificuldades trazidas a esta mesa de debates, pois na escassez de trabalhos de epistemologia da comunicação, ou seja, de epistemologia aplicada, é em relação às correntes da epistemologia geral que devemos situar o saber comunicacional (...). É incontestável a pouca sensibilidade dessa área (a Comunicação) para os problemas da fundamentação dos conhecimentos aí produzidos. É forte o sentimento de que a Comunicação deva ser considerada apenas como uma disciplina sui-generis; e mesmo quando se admite considerá-la como disciplina científica, persiste ainda o sentimento de que deva ser considerada apenas como uma ciência aplicada, uma vez que seu saber e sua cientificidade são derivados de outros saberes". (Martino, 2003: 82-83) 
E é no seio de diversos aportes para a área de Comunicação (e como um apêndice da mesma) e no manancial de informações que circulam pela Internet que surge o seguinte questionamento: no que consiste o jornalismo praticado na atualidade? Haja vista um espaço onde toda e qualquer informação - de qualidade ou não - pode ser divulgada e as pessoas são atraídas pelos assuntos de seu interesse, recebendo mensagens segundo a sua própria vontade, diferente da tirania que os grandes veículos de comunicação de massa impuseram em nossa maneira de ver e interpretar o mundo. Será que estamos próximos do fim dessa profissão?

$\mathrm{Na}$ academia, filho pobre das também chamadas "ciências da comunicação", o jornalismo congrega pesquisadores que vieram da redação para a academia, que trazem as mãos sujas pela graxa das antigas e obsoletas oficinas, contaminadas pela imundice do mercado, de acordo com alguns comunicólogos mais voltados às "teorias puras". Congrega também egressos de cursos de Comunicação que pouco - ou jamais - tiveram experiência profissional. De todo modo, a pesquisa em jornalismo se faz presente com maior ou menor aceitação na academia (há um folclórico dito, sobre a convivência da comunicação com o jornalismo nas universidades: trata-se da Sourbonne e do Senai, respectivamente...).

Preconceitos à parte, o jornalismo precisa ser discutido em suas bases. $\mathrm{E}$ é uma discussão de difícil encaminhamento já que, assim como a comunicação - e, mais precisamente, colocado como um apêndice dela - carrega problemas de base quanto aos atributos científicos, ou seja, quanto à possibilidade de ganhar o status de objeto, disciplina ou ciência.

"Somente depois da primeira geração de pesquisadores formada nos cursos de pós-graduação, tendo destaque nomes como Marques de Melo, Muniz Sodré, Nilson Lage, Ciro Marcondes e Cremilda Medina, entre outros, são dados os primeiros passos para o desenvolvimento da pesquisa conceitual no campo do jornalismo. A experiência acumulada ao longo dos último 30 anos de formação pós-graduada revela que, com poucas exceções, falta uma sistematização sobre a natureza do fenômeno jornalismo", afirma Machado. 


\section{De interdisciplinaridades, transdisciplinaridades, multidisciplinaridades, transversalidades...}

Ao se discutir a pesquisa em Comunicação fala-se - e muito se escreve, também - em interdisciplinaridade, transdisciplinaridade, multidisciplinaridade, transversalidade, termos que dariam base, por vezes, ou justificariam, por outras, a adoção de conceitos e métodos de outras ciências para a pesquisa na pós-graduação, mais especificamente.

Aqui e ali estes termos são pinçados para justificar a adoção desta ou daquela trilha conceitual ou metodológica e, também, para a não adoção de trilha alguma.

"A transversalidade e a interdisciplinaridade são modos de se trabalhar o conhecimento que buscam uma reintegração de aspectos que ficaram isolados uns dos outros pelo tratamento disciplinar. Com isso, busca-se conseguir uma visão mais ampla e adequada da realidade, que tantas vezes aparece fragmentada pelos meios de que dispomos para conhecê-la e não porque 0 seja em si mesma”.(Martin Garcia, 2002: 82-84)

Já o termo transdisciplinaridade pode ser definido como "uma nova abordagem científica, cultural, espiritual e social. Como o prefixo "trans" indica, diz respeito àquilo que está ao mesmo tempo entre as disciplinas, através das diferentes disciplinas e além de qualquer disciplina. Seu objetivo é a compreensão do mundo presente, para a qual um dos imperativos é a unidade do conhecimento. O Manifesto da Transdisciplinaridade é a primeira obra sintética sobre a abordagem transdisciplinar, cujo interesse está se alastrando por toda a parte. Ele se endereça a todos os homens e a todas as mulheres que crêem ainda, apesar de tudo, num projeto futuro além de todo dogma e toda a ideologia. (...) Esse processo implica uma abertura multidimensional da Universidade em direção à sociedade civil; em direção a outros lugares de produção do novo conhecimento; em direção ao espaço-tempo cibernético; em direção aos objetivos da universalidade; em direção à redefinição dos valores que governam sua própria existência. (...) A disciplinaridade, a multidisciplinaridade, a interdisciplinaridade e a transdisciplinaridade são como quatro flechas lançadas de um único arco: o conhecimento". 
Ao se falar em transdisciplinaridade, é importante citar o "Novo Pacto da Ciência, Primeiro Seminário Transdisciplinar - A Crise dos Paradigmas", organizado pela prof. dra. Cremilda Medina, na Escola de Comunicações e Artes da Universidade de São Paulo, na década de 90. O evento reuniu pesquisadores como Atílio Vanin, José Carlos Bruni, Milton Greco e outros, de diferentes áreas do conhecimento: "Todos os cientistas do Primeiro Encontro Transdisciplinar são unânimes ao se flagrarem aprendizes da epistemologia da complexidade". (Medina, 1991)

Não faltam críticas, no entanto, aos modelos até aqui colocados, especialmente no que diz respeito à interdisciplinaridade (Gomes, 2003: 328): "Nada há de interdisciplinar nisso ainda que o jargão da interdisciplinaridade sirva para encobrir a dignificar sua fragilidade. O elogio do ensaio como forma, o discurso da crise de paradigmas e o jargão da interdisciplinaridade são ao mesmo tempo sintoma e causa das fragilidades epistemológicas que dificultam a consolidação da nossa área", alerta Gomes.

Ancoradas não raras vezes neste termo - interdisciplinaridade - muitas das pesquisas no setor se mostram, não raras vezes e cientificamente falando, bastante frágeis (a análise mais detida neste sentido vem sendo investigada ao longo do referido trabalho de pesquisa pessoal).

O que vem a ser essa interdisciplinaridade colocada por alguns pesquisadores da área? De qual interdisciplinaridade falam?

"De fato, interdisciplinar é uma palavra tão mal compreendida hoje quanto multiculturalismo, e por razões semelhantes. Ambas as palavras aparecem, a seus detratores, derrubar fronteiras e hierarquias, nivelar diferenças em lugar de traças distinções entre elas, parecem convidar a uma ausência de rigor e ameaçar, de algum modo - apagar ou destruir o termo raiz (cultura, disciplina)". (Garber, 2003: 76)

"Estudos interdisciplinares, assunto de que tanto ouvimos falar (...) não representam meramente um confronto com as disciplinas já constituídas (as quais, na verdade, não admitem sair de cena). A fim de fazer um trabalho interdisciplinar, não basta tomar um 'objeto' (tema) e dispor duas ou três ciências em redor dele. $O$ estudo interdisciplinar consiste em criar um objeto novo, que não pertence a ninguém". (Garber, citando Barthes) 
Garber tenta reunir elementos que fundamentem o debate: "Ainda ouvimos falar muito, talvez até demais, sobre estudos interdisciplinares: como são desejáveis, impossíveis, inevitáveis e como cortejam a impostura. Num ensaio na revista Profession de MLA, Stanley Fish afirmou que, quando alguém diz que está fazendo estudos interdisciplinares, está [1] tomando emprestadas técnicas de outras disciplinas para executar as tarefas de sua própria disciplina ou [2] trabalhando no âmbito de uma disciplina num momento em que esta expande suas fronteiras e metodologias (...), ou [3] criando uma nova disciplina, 'que assume a tarefa de analisar as disciplinas'e que, desse modo, leva a cabo seu projeto ao mesmo tempo em que o põe em questão". (Garber, 2003: 74)

Como podemos observar, tal discussão vem sendo feita esporadicamente por pesquisadores e docentes, em encontros acadêmicos, muitas vezes sem a profundidade necessária e sem que se chegue a uma unidade conceitual mínima que contemple todas as chamadas linhas de estudo em torno da Comunicação. Isso significa que as pesquisas na área não apresentam aparentemente alguma coerência quanto a termos, conceitos e metodologia. $O$ que dizer, então, daquelas que tratam do Jornalismo?

"O primeiro problema que assombra o pesquisador em Comunicação, preocupado em perceber a área em que trabalha - para se situar com alguma identidade acadêmica - é a de caracterizar, afinal, qual é o objeto de conhecimento que a define", assinala Braga. (Braga, 2001: 14)

É de fundamental importância avançar no campo de conhecimento no qual atuamos, como docentes e pesquisadores, já que, aparentemente, "entre o status de ciência constituída ou apenas como um campo de interseção de saberes diversos, o estatuto da Comunicação Social tem variado ao longo das décadas e dividindo opiniões. (...) Em contraste, então, com outros saberes constituídos, sua entrada na cena intelectual não se deveu à consistência de sua fundamentação teórica, mas sim a uma forte demanda social" . (Martino, 2001: 51) 


\section{Dados preliminares}

De acordo com dados preliminares da referida pesquisa pessoal, o cenário em torno da discussão até aqui colocada não é nada róseo. $\mathrm{E}$ precisamos enfrentá-lo. De um total 26 foram trabalhos recolhidos e lidos (dissertações de mestrado, teses de doutoramento e de pós-doutoramento dedicadas ao tema - jornalismo on line - defendidas desde 1995 até 2003), 16 foram excluídos da pesquisa por não apresentarem pertinência aos objetivos aqui propostos. Explicando, nos trabalhos retirados da amostra, as palavraschave jornalismo, on line, jornalismo on-line, jornalismo na internet, jornalismo digital, que constituíram a base de busca informatizada, não eram objeto ou preocupação central de tais estudos.

Assim, o corpus passou a ser composto de 10 (dez), encontrados em bibliotecas de três cursos de pós-graduação em Comunicação em Comunicação, da região metropolitana de São Paulo. Foram visitadas as bibliotecas da Escola de Comunicações e Artes da Universidade de São Paulo (ECA/USP); da Pontifícia Universidade Católica de São Paulo (PUC-SP); e da Universidade Metodista de São Paulo.

Inicialmente, podemos afirmar que em um período de 8 (oito) anos, considerando os trabalhos disponíveis nas bibliotecas de três universidades tradicionais e representativas para a pesquisa em Comunicação e Jornalismo no País, apenas 10 (dez) trabalhos se dedicaram efetivamente a investigar 0 jornalismo on line.

Isso pode demonstrar que a produção acadêmica sobre jornalismo on line foi, neste período, tímida, tendo em vista o impacto das transformações no setor e a necessidade de compreensão melhor do fenômeno.

Mais que isso, como também pretendemos demonstrar, os trabalhos produzidos em torno do tema pouco se aprofundaram no jornalismo enquanto conceito e, parece mais grave, utilizaram uma metodologia que se mostra frágil até mesmo quando empregada para a pesquisa do jornalismo nos suportes anteriores (papel, rádio e televisão) à Internet.

Inicialmente, foram xerocopiados todos os trabalhos encontrados e, posteriormente, de cada um, a bibliografia utilizada e as partes nas quais os autores tentam explicitar conceitos, termos e metodologia (quando isso 
acontece). Seguem os dados preliminares, obtidos com amparo no instrumental metodológico da análise de conteúdo.

\section{Dados obtidos na primeira leitura do corpus (leitura inicial, flutuante, como propõe Bardin)}

*Numa leitura inicial dos trabalhos, observamos que nem todos trazem um capítulo explicitando termos, conceitos e especialmente a metodologia utilizada.

*Também foi possível constatar que alguns destes trabalhos sequer citam livros de metodologia nas referências bibliográficas ou na bibliografia geral.

*Ficou claro que as técnicas preferidas para análise, por parte dos autores, ficam por conta da aplicação de questionários e de entrevistas junto a diversas fontes. A opção pelo "estudo de caso" como método é o caminho mais utilizado pelos pesquisadores.

*Todos os trabalhos, em algum momento, falam sobre jornalismo e/ou notícia, ou informação. No entanto, apenas dois deles discutem estes termos enquanto conceitos importantes para fundamentar sua pesquisa. Em todos os trabalhos predominam, em contrapartida, capítulos contando a história da Internet e descrevendo, à exaustão, o funcionamento desta nova mídia. Em outras palavras, a preocupação em descrever as novas tecnologias da informação suplanta a preocupação em discutir as bases do fazer jornalístico, o que daria um suporte consistente para as referidas pesquisas.

*Até este momento da minha análise, posso notar, nitidamente, a preocupação dos autores dos trabalhos observados em encontrar "fórmulas" para melhor adaptar o jornalismo que é feito em outros suportes para este novo espaço, a WEB. Isso pode revelar uma tendência possível: a pesquisa aplicada e acrítica para o setor. É cedo para fazer uma afirmação desse porte, mas é uma possibilidade que vai merecer bastante atenção nas próximas leituras, já que estamos falando aqui de 50\% (metade do material) do universo. 
Outro fator sintomático - no que diz respeito à discussão do "campo" ou "objeto" jornalismo - que pude observar durante as leituras iniciais: alguns trabalhos poderiam ser vistos, sem problemas, como uma reportagem, dada a falta de preocupação em explicitar as escolhas metodológicas.

De qualquer maneira, são apenas hipóteses diante de uma primeira leitura, e parece prematuro generalizar estas observações sem proceder à análise completa do material. Porém, são pistas importantes que devem nortear a leitura e a análise final do corpus desta pesquisa. Vale destacar, final e preliminarmente, que dada à extensão do período escolhido, são poucos (26 ao longo de 9 anos) os trabalhos que referem aquelas palavras-chave, nas três universidades escolhidas, principalmente se levarmos em conta que nem todos abordam primordialmente o jornalismo.

Dados obtidos numa segunda leitura do corpus (leitura parcialmente organizada, a título de hipóteses provisórias):

Vejamos a análise parcial do corpus, ou seja, os dados preliminares obtidos, numa segunda leitura (a pesquisa deve ser concluída numa terceira leitura):

* Apresentaram uma discussão em torno de metodologia, explicitando as escolhas das técnicas empregadas, apenas cinco trabalhos, entre os quais, alguns de maneira equivocada, tomando técnica por metodologia. De todo modo, isso demonstra que metade da produção científica analisada não discute opções metodológicas e/ou, parece mais grave, toma o termo técnica por metodologia.

* A discussão fundamental, em torno de conceitos do jornalismo é feita em apenas dois trabalhos, ou seja, oito trabalhos deixam de lado essa fundamentação, revelando até mesmo despreocupação com ela, como se conceitos de jornalismo já estivessem suficientemente discutidos e o leitor do trabalho pudesse escolher qualquer um deles para compreender a fala do autor. Esses conceitos são tratados como se o seu domínio fosse óbvio, simples.

* Alguns conceitos em torno da prática jornalística (produção de notícia, reportagem, gêneros, lead etc) são abordados em seis trabalhos, não raras 
vezes, o que é preocupante, com os autores tomando-os como equivalentes a conceitos e/ou teorias de jornalismo.

\section{Conclusão}

Estes dados sugerem que, na maior parte dos trabalhos analisados, os pesquisadores supõem uma clareza indiscutível sobre a natureza do jornalismo, quer como atividade ou como campo científico, ou ainda como disciplina. Para os cientistas estudados aqui, não seria necessário discutir bases teóricas que fundamentam o jornalismo para a pesquisa científica.

Após esta leitura do corpus e descrição dos primeiros dados obtidos e referentes à discussão de bases teóricas e metodológicas para a pesquisa no setor, continuamos, dentro do cronograma proposto, no propósito de aprofundar a análise estabelecendo, como propõe Bardim, categorias temáticas para isso.

Assim, a proposta é a de analisar ainda a bibliografia e os autores mais freqüentemente citados na fundamentação teórica e metodológica de todos os trabalhos que compõem esse corpus, a fim de analisar a relação entre estes autores e entre eles e o jornalismo; detectar termos usuais em teses e dissertações em jornalismo (tais como linguagem, notícia, informação) verificando se estão explicitados pelos pesquisadores ou, ainda, se são tomados como sinônimos; e finalmente estabelecer relações entre os dados obtidos.

Espera-se, ao término desta pesquisa pessoal, previsto para o final deste ano, incentivar uma retomada dos estudos mais aprofundados sobre o tema, e ao mesmo tempo, dimensionar mais adequadamente a pesquisa acadêmica em jornalismo, contribuindo para que ela retome a importância e o lugar que ocupou nos tempos de Groth e Peucer. E, tudo indica, isso significa que ela precisa deixar de ser apenas uma "disciplina" do "campo" da Comunicação. 


\section{Referências bibliográficas}

BARDIN, Laurence. Análise de conteúdo, edições 70, Lisboa, 1977.

BARTHES, Roland, citado por Garber, Marjorie, Instintos acadêmicos, ed. UERJ, Rio de Janeiro, 2003. Pág. 74.

BASARAB, Nicolescu, autor do "Manifesto da transdisciplinaridade". Conferência no congresso international "A responsabilidade da universidade para com a sociedade", International Association of Universities, Chulalongkorn University, Bangkok, Thailand, de 12 a 14 de novembro de 1997.

BRAGA, José Luiz, in Neto, Antônio Fausto; Prado, José Luiz Aidar e Porto, Sérgio Dayrrel; organizadores. Vários. Campo da comunicação caracterização, problematizações e perspectivas, editora Universitária/UFPB, João Pessoa, Paraíba, 2001.

FRANÇA, V.R.V. "Teoria(s) da comunicação: busca de identidade e de caminhos". Belo Horizonte: Depto. de Comunicação da UFMG, 1994.

GARBER, Marjorie. Instintos acadêmicos, ed. UERJ, Rio de Janeiro, 2003.

GOMES, Wilson. "O estranho caso de certos discursos epistemológicos que visitam a área de comunicação", in: LOPES, Maria Immacolata Vassalo de (org), Epistemologia da comunicação, ed. Loyola, São Paulo, 2003.

MACHADO, Elias. O ciberespaço como fonte para os jornalistas, editora Calandra, Salvador, 2003.

MARTIN GARCIA, Lenise Aparecida. Transversalidade. presença pedagógica.

Belo Horizonte: v.8, n.45, 2002.

MARTINO, L. C. in: NETO, Antônio Fausto; PRADO, José Luiz Aidar e PORTO, Sérgio Dayrrel; organizadores. Vários. Campo da comunicação caracterização, problematizações e perspectivas, editora Universitária/UFPB, João Pessoa, Paraíba, 2001.MEDINA, Cremilda (org.). "Novo pacto da ciência.a crise dos paradigmas - primeiro seminário interdisciplinar", Anais, USP/ECA, 1990-1991.

MELO, José Marques de. "Ensino de Graduação em Comunicação Social: paradigmas curriculares". Revista Brasileira de Ciências da Comunicação, Identidades comunicacionais, ano XXI, número 01, janeiro/Juno de 1998, Intercom, São Paulo.

MOLES, Abraham A. As ciências do impreciso, Civilização Brasileira, RJ, 1990. p. 62.

NEGROPONTE, N. A Vida Digital, São Paulo, Cia das Letras, 1996.

PEUCER, Tobias. "Os Relatos Jornalísticos" (tradução de Paulo da Rocha Dias), Estudos em Jornalismo e Mídia, p. 13-30, volume I, no 02, Editora Insular, SantaCatarina, 2004.

PROENÇA, José Luís, "A Capes e o enterro da Periodika", Artigo publicado no Jornal da USP, ano XIX, n. 670, 15/12/2003, p. 2.

Ciberlegenda, revista eletrônica, № $03, \quad$ 2001, http://www.uff.br/mestcii/muniz1.htm

\footnotetext{
1 Trabalho apresentado ao XXX Encontro dos Núcleos de Pesquisa em Comunicação - NP- Jornalismo. No XXX Congresso Brasileiro de Ciências da Comunicação - Intercom 2007.
} 
${ }^{2}$ A autora é jornalista e trabalhou em jornais impressos diários na cidade de São Paulo como Folha e $S$. Paulo e Jornal da Tarde. Há oito anos é docente (graduação e pós-graduação) e pesquisadora na ECAUSP, Departamento de Jornalismo e Editoração, onde obteve os títulos de mestre e doutora em Ciências da Comunicação.nali@uol.com.br

${ }^{3}$ World Wide Web, método de criar e trocar documentos com gráficos e fotos via Internet, criado pelo físico Tim Berbers-Lee, na Suíça, em meados da década de 80. 